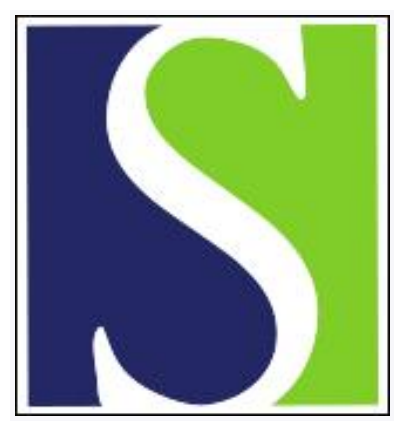

Scand J Work Environ Health 2019;45(3):213-214

https://doi.org/10.5271/sjweh.3825

Published online: 10 Apr 2019, Issue date: 01 May 2019

Binding occupational exposure limits for carcinogens in the EU - good or bad?

by Johanson $\mathrm{G}$, Tinnerberg $\mathrm{H}$

Affiliation: Unit of Integrative Toxicology, Institute of Environmental Medicine, Karolisnka Institutet, Stockholm, Sweden. gunnar.johanson@ki.se

The following articles refer to this text: 2019;45(4):423-424;

2020;46(1):110-112

Key terms: cancer; carcinogen; editorial; exposure; exposure limit; exposure limit value; occupational cancer; occupational exposure; occupational exposure; work-related cancer

This article in PubMed: www.ncbi.nlm.nih.gov/pubmed/30969344 


\section{Binding occupational exposure limits for carcinogens in the EU - good or bad?}

The European Union (EU) has increased its efforts to counteract cancer due to occupational exposure. This is done by several means, including more active use and revision of the Carcinogen Directive (1), launch of the Roadmap on Carcinogens (2) and the Fight Against Occupational Cancer initiative (3). These are important steps, as more than 100000 workers die each year from work-related cancer in Europe (4). The top seven exposures responsible for these cancers are asbestos, shift work, mineral oils, solar radiation, silica, diesel exhaust, and polyaromatic hydrocarbons. One important measure is to introduce so-called "binding occupational exposure limit values" (BOELV), which are mainly set for nonthreshold carcinogens. BOELV have to be implemented, at a minimum, in the work environment legislation of the EU member states. Recent efforts have resulted in an increase in BOELV from 6 substances in 2003 (Directive 98/24/EC) to 16 in 2017 (Directive 2017/2398), including, eg, hexavalent chromium (Cr VI), respirable crystalline silica, benzene, and 2-nitropropane. BOELV set in 2017 must be implemented in national law by 2020.

The EU-established BOELV were largely based on evaluations (formerly called summary documents, more recently recommendations) carried out by the Scientific Committee on Occupational Exposure Limits (SCOEL). When possible, SCOEL recommends health-based occupational exposure limits (OEL) to the Commission, however, for non-threshold carcinogens, a safe level cannot be identified. In these cases, SCOEL instead calculates life-time extra cancer risks for different exposure levels (5).

In comparison with the US Occupational Safety and Health Administration (OSHA) (silica) and SCOEL's (2-nitropropane and $\mathrm{Cr} \mathrm{VI}$ ) risk assessments, we find that the estimated cancer risks following exposure at BOELV are extremely high for some of the substances. For example, the OSHA estimates that 45 years of workplace exposure to respirable crystalline silica at the BOELV of $0.1 \mathrm{mg} / \mathrm{m}^{3}$ would cause 11-54 deaths from lung cancer and, in addition, 85 deaths from non-malignant respiratory diseases, and 39 deaths from kidney disease per 1000 workers (6). In fact, these OSHA calculations most likely underestimate the true risk as they do not account for the healthy worker survivor effect (7). Regarding 2-nitropropane, exposure to nitropropane at the BOELV of $5 \mathrm{ppm}$ would result in tumors in 28 out of 1000 workers, according to our recalculation from the SCOEL recommendation (8). Maybe the most controversial and debated BOELV is that of Cr VI. The proposed BOELV was initially $0.025 \mathrm{mg} / \mathrm{m}^{3}$, but after much criticism, the value was lowered to $0.005 \mathrm{mg} / \mathrm{m}^{3}$. The latter value would still result in 20 lung cancers per 1000 workers according to SCOEL (9). The high risk of cancer and the BOELV for Cr VI have caused an intense debate in the Netherlands and Denmark, with extensive attention in major daily newspapers and even at ministerial level.

If the risks are so high, then why are BOELV not set lower? One reason might be that the decision-makers think that SCOEL's cancer risk estimates are overly conservative (ie, the experts are exaggerating the risk at workplace relevant exposure levels). This might indeed be the case for some substances where SCOEL used linear extrapolation to zero concentration, while the true risk might be lower than proportional (sublinear or hockey stick) or even zero up to a certain exposure concentration (threshold). However, SCOEL used the best available toxicological and epidemiological data in their assessments, and it seems difficult to find any alternative ways of scientifically sound risk calculation, unless new data emerges. In any case, the assumption of exaggerated risk is not valid for crystalline silica, for which there is epidemiological evidence of mortality also around the BOELV.

Another argument would be that it is unrealistic to assume that workers are exposed to the chemical at the BOELV their whole working life (ie, 40 hours per week for 40 years). We agree that this assumption is unrealistic in most cases, 
however, it forms the basis for setting OEL, as stated for example in the SCOEL methodology (5). Moreover, as retirement age increases, an individual's actual working years might stretch beyond 40 years in some cases. Furthermore, long work shifts, for example 14 days in a row with 12 hours per day, have become common in some type of work. In any case, it seems very strange to maintain a high limit value with the argument that workers are far less exposed in practice. A third argument is that, regardless of the numerical value, the establishment of a BOELV acknowledges that the chemical is a dangerous carcinogen and that measures should be taken to minimize the exposure as far as possible (the ALARA principle: as low as reasonably possible). The problem of having a too-high limit value is that it gives a false sense of protection. Further arguments put forward are that the present BOELV are just a first step. New toxicological data and technical improvements may well lead to lowered values in the future, and BOELV are minimal requirements, so member states may introduce lower values if they wish. The future will tell if this will happen. Most EU member states lack the resources to develop OEL on their own. Sweden, for example, disbanded their expert group a few years ago, with the understanding that this work is carried out at the EU level and therefore unnecessary at the national level.

So, are the new EU BOELV good or bad? Well, certainly they are a start, and maybe even a good one at that. However, in our opinion, some of the limits are outrageously high and breach the fundamental rights of safe and healthy working conditions $(10,11)$. Moreover, there are still very few binding values, many more are needed in order to protect workers more thoroughly against occupational cancer.

\author{
Gunnar Johanson \\ Unit of Integrative Toxicology \\ Institute of Environmental Medicine \\ Karolisnka Institutet \\ Stockholm, Sweden \\ [Email: gunnar.johanson@ki.se]
}

\author{
Håkan Tinnerberg \\ Department of Occupational \& Environmental Medicine \\ Sahlgrenska University Hospital \\ Gothenburg, Sweden \\ [Email: hakan.tinnerberg@amm.gu.se]
}

\section{References}

1. Directive 2004/37/EC of the European Parliament and of the Council of 29 April 2004 on the protection of workers from the risks related to exposure to carcinogens or mutagens at work (Sixth individual Directive within the meaning of Article 16(1) of Council Directive 89/391/EEC). Luxembourg: Office for Official Publications of the European Union. https://eur-lex.europa.eu/LexUriServ/LexUriServ. do?uri=OJ:L:2004:229:0023:0034:EN:PDF

2. Roadmap on Carcinogens. Available from roadmaponcarcinogens.eu

3. Fight against Occupational Cancer Conference, Vienna 24-25 September 2018. https://www.eu2018.at/calendar-events/politicalevents/BMASGK-2018-09-24-Conf.Carcinogens.html

4. Takala J. Eliminating occupational cancer in Europe and globally. OSH Wiki. Available from https://oshwiki.eu/wiki/Eliminating _ occupational_cancer_in_Europe_and_globally

5. European Commission. Methodology for derivation of occupational exposure limits of chemical agents The General Decision-Making Framework of the Scientific Committee on Occupational Exposure Limits (SCOEL); 2017. https://circabc.europa.eu/sd/a/99a19e17b82e-4c9e-91cd-458818f4f915/SCOEL\%20methodology\%202017.pdf

6. OSHA. Occupational Exposure to Respirable Crystalline Silica. Federal Register / Vol. 81, No. 58 / March 25, 2016 / Rules and Regulations. https://www.govinfo.gov/content/pkg/FR-2016-03-25/pdf/2016-04800.pdf

7. Keil AP, Richardson DB, Westreich D, Steenland K. Estimating the impact of changes to occupational standards for silica exposure on lung cancer mortality. Epidemiology 2018;29(5) 658-65. https://doi.org/10.1097/EDE.0000000000000867

8. SCOEL/REC/300 2-Nitropropane Recommendation from the Scientific Committee on Occupational Exposure Limits. 17 March 2018. https:/publications.europa.eu/en/publication-detail/-/publication/5824f230-0d3a-11e7-8a35-01aa75ed71a1/language-en

9. SCOEL/REC/386 Chromium VI compounds Recommendation from the Scientific Committee on Occupational Exposure Limits. 28 August 2017

10. European Parliament. Charter of Fundamental Rights of the European Union. 2000/C 364/01. http://www.europarl.europa.eu/charter/ pdf/text_en.pdf

11. United Nations. Universal Declaration of Human Rights. https://www.ohchr.org/EN/UDHR/Documents/UDHR_Translations/eng.pdf 